Marquette University

e-Publications@Marquette

Mathematical and Statistical Science Faculty

Mathematical and Statistical Science

Research and Publications

Department of

$12-1-2020$

\title{
Effects of Hand Preference on Digit Lengths and Digit Ratios Among Children and Adults
}

Sanjay Kumar

D.A.V. College

Maharaj Singh

Marquette University, maharaj.singh@marquette.edu

Martin Voracek

University of Vienna

Follow this and additional works at: https://epublications.marquette.edu/math_fac

\section{Recommended Citation}

Kumar, Sanjay; Singh, Maharaj; and Voracek, Martin, "Effects of Hand Preference on Digit Lengths and Digit Ratios Among Children and Adults" (2020). Mathematical and Statistical Science Faculty Research and Publications. 56.

https://epublications.marquette.edu/math_fac/56 
Marquette University

e-Publications@Marquette

\title{
Mathematics and Statistical Science Faculty Research and Publications/College of Arts and Sciences
}

This paper is NOT THE PUBLISHED VERSION.

Access the published version via the link in the citation below.

Early Human Development, Vol. 151 (December 2020): 105204. DOI. This article is (C) Elsevier and permission has been granted for this version to appear in e-Publications@Marquette. Elsevier does not grant permission for this article to be further copied/distributed or hosted elsewhere without the express permission from Elsevier.

\section{Effects of Hand Preference on Digit Lengths and Digit Ratios Among Children and Adults}

\author{
Sanjay Kumar \\ Department of Psychology, D.A.V. College, Muzaffarnagar, Uttar Pradesh, India \\ Maharaj Singh \\ Department of Mathematics and Statistical Sciences, Marquette University, Milwaukee, Wisconsin \\ Martin Voracek \\ Department of Basic Psychological Research and Research Methods, Faculty of Psychology, University \\ of Vienna, Vienna, Austria
}

\section{Abstract}

Background

Prenatal sex hormones may not exclusively determine effects of hand preference on digit ratios. Genetic determination is an alternative possibility. 


\section{Aim}

To study the likelihood of similar effects of hand preference on digit lengths and digit ratios.

\section{Methods}

We selected similar numbers of left-handers and right-handers in samples of kindergarten children $(N=101$, age range: $3.5-7$ years) and adults ( $N=189$, age range: $17-28$ years) and measured digit lengths (excluding the thumb) directly on the palmar hand.

\section{Results}

Compared to right-handers, left-handers had longer digits and lower third-to-fourth (3D:4D) digit ratios among children, whereas an opposite pattern of handedness differences occurred among adults.

\section{Conclusions}

Effects of hand preference on digit lengths and ratios might be genetically/ontogenetically determined. Also discussed are implications of this set of findings for digit ratio research.

\section{Keywords}

Digit length; Digit ratio; Age; Hand preference; Laterality

\section{Introduction}

Prenatal androgen levels appear to be related to lower second-to-fourth digit ratio (2D:4D; $[\underline{1}, \underline{2}])$ and also are a likely determinant of left-handedness (higher level [3]]; lower level [4]]). Thus, a relationship between hand preference and 2D:4D ratio is expected. However, studies have reported contradictory patterns of associations. Some studies have reported lower 2D:4D ratios [토의, whereas other higher 2D:4D ratios (in the left hand, [7]; in the right hand, [8]; in both hands, $[\underline{9}, \underline{10}])$ in left-handers, as compared to right-handers. Several studies have failed to report relationships between hand preference and 2D:4D [[11], [12], [13], [14], [15]]. In addition, there is a lack of relationship between cerebral lateralization and 2D:4D [[16], [17], [18]]. Thus, the support for a major role of prenatal sex hormones in determining hand-preference effects on digit ratios is equivocal.

However, interestingly, irrespective of the pattern of effects of hand preference on digit ratios, some of the above-mentioned studies have reported a similar pattern of effects of hand preference on right, as compared to left, 2D:4D ratio (Dr-l; lower values for left-handers; $[\underline{7}, \underline{11}, \underline{14}, 15])$. Because Dr-I may be an additional marker of prenatal androgen levels [19], these findings may well suggest a role of prenatal sex hormones in the determination of effects of hand preference. However, larger and better-controlled studies have failed to find a relationship of prenatal androgen levels with Dr-I [20,21]. Moreover, in comparison to Dr-I, the effect of biological sex (a better test of sex-hormone effects) is much stronger in digit ratios [22,23]. Thus, perhaps 2D:4D and Dr-I reflect two different effects and 2D:4D is a better marker of prenatal sex hormones. Therefore, in the present study, we focused on digit ratios, which are widely studied suggested proxies of prenatal sex-hormone levels.

Noticeably, a large proportion of variance in digit ratios (2D:4D) is genetically determined [[24], [25], [26], [27]]. Second-to-fourth digit ratio is closely related to a gene variant (LIN28b; [28]) that determines height and age of menarche [29]. Studies have reported that, compared with right-handers, left-handers have early menarcheal onset $[30,31]$. Studies also have reported that height is related to digit lengths (positively, [22]), digit ratios (negatively with 2D:4D, [32]), and hand preference (lower in left-handers, [33, 34]). Moreover, pubertal growth is under tight genetic regulation [35], and a common gene program controls both pubertal timing and bone 
development $[\underline{29}, \underline{36}]$. Hence, it is not unlikely that a common gene mechanism might determine effects of hand preference on digit lengths, digit ratios, and age of onset of puberty. Perhaps a simple test of this is the occurrence of similar effects of hand preference on digit lengths and digit ratios.

Consistent with this, previous reports of similar effects on digit lengths and ratios were incongruent with the sex-hormones determination hypothesis (effects of prenatal alcohol exposure in rats, [37]; effects of musical ability, [38]; effects of azoospermia, [39]). Although a large number of studies have reported differences in digit ratios for the characteristics presumably determined by prenatal sex hormones (e.g., reviewed in [40]), these studies have not reported on differences in digit length (although digit lengths are the essential measures for calculating digit ratios). Moreover, irrespective of the different effects on digit length (strong among adults, but not among children), the effect of sex (female, male) on digit ratios appears to be comparable among children and adults $[9,41]$. Thus, the effect of prenatal sex hormones is most likely to be limited to relative digit length (i.e., digit ratios) and therefore may not account for similar effects observed on digit lengths.

In the context of controlling suspected effects of sex hormones (prenatal and pubertal), investigating effects of hand preference on digit lengths and digit ratios among children as well as among adults is important (as the effect of biological sex is similar for digit ratios, but dissimilar for digit length). Because age-related changes seem to occur in digit ratios as well $[\underline{41}, \underline{42}]$, the study of groups with a discrepancy in age and development (i.e., children vs. adults), may be more informative and better controlled. Furthermore, only a few studies have focused on effects of hand preference on digit ratios among children, and the findings have been ambiguous (Fig. 2, p. 330 [9]). However, prior studies have reported a consistent relationship between right-handedness and higher digit ratios among young children $[\underline{43}, \underline{44}]$.

Intriguingly, most prior studies have focused on effects of hand preference on 2D:4D exclusively, whereas investigating other digit ratios than the commonly studied 2D:4D theoretically and methodologically is advantageous (for discussion, see [[45], [46], [47], [48]]). One study of multiple digit ratios has reported that, rather than the 2D:4D ratio, digit ratios comprising digit 5 as the denominator are smaller in left-handers vs. right-handers (among women, [49]). Because hands and fingers develop through a coordinated gene program working on axes [50], the study of phenotypic measures representing whole axes, such as the study of several digit lengths and several digit ratios, would be more informative. In addition, some studies have reported that geographic (ethnic-group) differences are related to noticeable variation in 2D:4D $([\underline{51}, \underline{52}])$. Therefore, geographic variations could be a confounding factor.

Thus, in the present study, we studied the possibility of similar effects of hand preference on digit lengths (of all digits, except the thumb) and on digit ratios (in all derivable digit ratios) in two different age groups (kindergarten children vs. adults; a non-directional hypothesis). Because samples were derived from the same catchment area (in the same district, and with a predominantly native population), we explored age-group effects on digit lengths and digit ratios as well. Moreover, because several studies have reported similar effects of hand preference on Dr-l, we also studied the effects of hand preference on right-minus-left digit ratio (across all derivable digit ratios).

\section{Materials and methods}

\subsection{Participants}

\subsubsection{Children sample}

A sample of 101 children (age: $M=5.1$ years, $S D=0.97$, range: $3.5-7$ years; $88 \%$ Hindus, $12 \%$ Muslims) was selected from public schools in Muzaffarnagar (a city in Western Uttar Pradesh, India). Participant breakdown was as follows: 48 boys, 53 girls, 57 right-handers, and 44 left-handers. Age and health status of children were determined from school records. Children without major neurological problems or hand injuries were included 
in the sample. At the time of data collection there was no institutional ethics committee; the D.A.V. College Ethics Committee approved the conducted study retrospectively. The participating children provided verbal informed consent, and parents provided written informed consent for their children's participation.

Initially, teachers identified left-handed children in the class. Left-handed children and their friends or deskmates were assessed in a room within the school premises. Hand preference was assessed with the observed hand-preference technique. Observed hand preference yields a factor structure similar to that found in questionnaire studies [53]. The ten items administered and the procedures used were the same as in Singh et al. [53]. Moreover, following Singh et al. [53], we classified participants with positive laterality quotient (LQ) scores as right-handers (LQ: $M=95.4, S D=6.3$ ), whilst those with zero or negative LQ scores as left-handers (LQ: $M=-$ $86.9, S D=16.1)$.

\subsubsection{Adult sample}

A sample of 189 college students (age: $M=21.6$ years, $S D=3.1$, range: $17-28$ years; $94 \%$ Hindus, $6 \%$ Muslims) was selected from Muzaffarnagar, which is an agriculture trade-based small city with a population mainly comprising the natives of the city and nearby villages (there are no major national-level institutes or enterprises). Therefore, the ethnic composition of the college student sample conceivably was similar to the one of the children sample selected from the schools. Sample composition was as follows: 94 men, 95 women, 100 right-handers, and 89 left-handers. As above, individuals without neurological problems or hand injuries were included in the sample. Participants provided written informed consent for study participation.

An advertisement was placed on the college notice boards, inviting left-handers to visit the psychology laboratory for participating in a study on hand measures. Generally, one or more right-handed friends accompanied them to the laboratory. Left-handers and their friends were assessed for hand preference, using a 14-item questionnaire (similar to Oldfield [54]; for details, see [55]). Similar to the procedure followed in the children sample, we identified right-handers (LQ: $M=86.2, S D=14.6$ ) and left-handers (LQ: $M=-$ $60.5, S D=32.4)$.

\subsection{Measurement of digit lengths and calculation of digit ratios}

Digit length (D) involves the distance between the tip of the finger and the basal crease of the proximal phalanx. Participants rested their hands with the palmar (i.e., inner) side up on a smooth table for a direct measurement of the lengths of their second to fifth digits (2D, 3D, 4D, and 5D) in both their hands, using vernier calipers with $0.1 \mathrm{~mm}$ accuracy level. From these finger-length measurements, we calculated all six possible digit ratios (namely, 2D:3D, the commonly studied 2D:4D, 2D:5D, 3D:4D, 3D:5D, and 4D:5D) for each hand (left and right). In addition, we derived all right-minus-left ( $\mathrm{Dr}-\mathrm{I})$ digit ratios corresponding to these six digit ratios in the right vs. left hand.

\subsection{Analysis}

We used multivariate analyses of variance (MANOVAs) for testing the effects of hand preference (left vs. right), sex (female vs. male), and age bracket (children vs. adults) on digit lengths (four per hand), on digit ratios (six per hand), and on the asymmetry in the latter ones (namely, right-left digit ratios; six measures in total). Following conventions in digit ratios research, we studied these effects on digit lengths and ratios separately for the right and the left hand. In addition, we provide effect sizes (Cohen $d$ and $\eta_{p}{ }^{2}$ ) for a better comprehension of the observed hand-preference effects. 


\section{Results}

\subsection{Left hand}

\subsubsection{Digit lengths}

Participant age showed a strong positive correlation with all digit lengths (all $r s>0.48, p<.001$ ) among children, but not among adults (all $r s<0.12, p>.11$ ). However, because effects remained the same with and without accounting for participant age, results are reported without age as a covariate.

A MANOVA of the four digit lengths, with hand preference, sex, and age group as factors, showed significant main effects of sex, $F(4,279)=9.9, p<.001, \eta_{p}{ }^{2}=0.12$, and age group, $F(4,279)=526, p<.001, \eta_{p}{ }^{2}=0.88$, and significant interaction effects of sex by age group, $F(4,279)=10.4, p<.001, \eta_{p}^{2}=0.13$, and hand preference by age group, $F(4,279)=5.23, p<.001, \eta_{p}{ }^{2}=0.07$. All other effects, $F s(4,279)<1.87, p s>0.12$, were not significant.

Thus, compared to right-handers, left-handers had longer digits among children, but slightly shorter digits among adults (hand preference by age group interaction; Table 1). As expected, adult men had longer digits than adult women, whereas there was no sex difference among children (sex by age group interaction; Table 1). Trivially, adults had longer digits than children (main effect of age group; Table 1). 
Table 1. Descriptive statistics of digit lengths in the left hand among children and adults.

\begin{tabular}{|c|c|c|c|c|c|c|c|c|c|c|c|c|c|c|}
\hline & & $\begin{array}{l}\text { Hand } \\
\text { preference }\end{array}$ & & & & & & Sex & & & & & & \\
\hline Left & & Right-handers & & $\begin{array}{l}\text { Left- } \\
\text { handers }\end{array}$ & & & $H \times A$ & Male & & Female & & $S \times A$ & & \\
\hline \multirow[t]{2}{*}{$\begin{array}{l}\text { Digit } \\
\text { length }\end{array}$} & $\begin{array}{l}\text { Age } \\
\text { group }\end{array}$ & $n=157$ & & $n=133$ & & & $F$ & $n=142$ & & $n=148$ & & $F$ & Total & \\
\hline & & $M$ & $S D$ & $M$ & $S D$ & $d$ & $\begin{array}{l}1, \\
282)\end{array}$ & $M$ & $S D$ & $M$ & $S D$ & $\begin{array}{l}1, \\
282)\end{array}$ & $M$ & $S D$ \\
\hline \multirow[t]{2}{*}{$2 \mathrm{D}$} & Ch. & 4.61 & 0.37 & 4.88 & 0.43 & $-0.68^{* *}$ & & 4.74 & 0.37 & 4.71 & 0.46 & & 4.73 & 0.42 \\
\hline & Ad. & 6.96 & 0.45 & 6.86 & 0.49 & 0.21 & 15.9 ** & 7.19 & 0.39 & 6.64 & 0.38 & $33^{* *}$ & 6.91 & 0.48 \\
\hline A, $F(1,282)$ & & & & & & & & & & & & & 1978*** & \\
\hline \multirow[t]{2}{*}{$3 \mathrm{D}$} & Ch. & 5.17 & 0.40 & 5.40 & 0.47 & $-0.53^{* *}$ & & 5.28 & 0.39 & 5.27 & 0.49 & & 5.27 & 0.44 \\
\hline & Ad. & 7.72 & 0.51 & 7.61 & 0.59 & 0.20 & $11^{* * *}$ & 8.01 & 0.45 & 7.34 & 0.42 & $42^{* *}$ & 7.67 & 0.55 \\
\hline A, $F(1,282)$ & & & & & & & & & & & & & $1942^{* *}$ & \\
\hline \multirow[t]{2}{*}{$4 \mathrm{D}$} & Ch. & 4.78 & 0.37 & 5.06 & 0.43 & $-0.71 * *$ & & 4.91 & 0.39 & 4.89 & 0.44 & & 4.90 & 0.42 \\
\hline & Ad. & 7.18 & 0.49 & 7.08 & 0.56 & 0.19 & 14.7 ** & 7.44 & 0.43 & 6.83 & 0.42 & $38^{* *}$ & 7.13 & 0.52 \\
\hline A, $F(1,282)$ & & & & & & & & & & & & & $1831^{\text {** }}$ & \\
\hline \multirow[t]{2}{*}{$5 \mathrm{D}$} & Ch. & 3.81 & 0.33 & 4.02 & 0.39 & $-0.59 * *$ & & 3.93 & 0.35 & 3.88 & 0.38 & & 3.91 & 0.37 \\
\hline & Ad. & 5.80 & 0.51 & 5.74 & 0.52 & 0.12 & $7.3^{* *}$ & 6.05 & 0.42 & 5.50 & 0.45 & $26 * *$ & 5.77 & 0.51 \\
\hline A, $F(1,282)$ & & & & & & & & & & & & & 1322 ** & \\
\hline
\end{tabular}

Note. 2D to 5D denote digit lengths; Ch. denotes children; Ad. denotes adults; A denotes main effect of age group; $\mathrm{H} \times \mathrm{A}$ denotes hand preference by age group interaction effect; $\mathrm{S} \times \mathrm{A}$ denotes sex by age group interaction effect; Positive value of $d$ shows that right-handers have longer digit length; Number of children = 101; Number of adults = 189; Number of right-handed adults = 100; Number of men = 94 .

**

$p<.01$. 


\subsubsection{Digit ratios}

A MANOVA of digit ratio (six digit ratios), with hand preference, sex, and age group as factors, showed significant main effects of hand preference, $F(6,277)=3.97, p=.001, \eta_{p}{ }^{2}=0.08$, and age group, $F(6$, $277)=2.5, p=.02, \eta_{p}{ }^{2}=0.05$, as well as a significant interaction effect of hand preference by age group, $F(6$, $277)=3.58, p=.002, \eta_{p}{ }^{2}=0.07$. All other effects, $F s(6,277)<1.13, p s>0.34$, were not significant.

Univariate ANOVAs showed an interaction effect between hand preference and age group on the 3D:4D ratio, $F(1,282)=4.4, p=.04, \eta_{p}^{2}=0.02$. Thus, in comparison to right-handers, left-handers had a lower 3D:4D ratio among children, but slightly higher 3D:4D among adults (Table 2 ). The main effect of hand preference on 3D:4D, $F(1,282)=5.6, p=.02, \eta_{p}^{2}=0.02$, merely reflects a lower digit ratio in left-handers among children (Table 2). Moreover, significant main effects of age group on $4 D: 5 D$ ratios, $F(1,282)=8.1, p=.005, \eta_{p}{ }^{2}=0.03$, and on 3D:5D ratios, $F(1,282)=5.9, p=.02, \eta_{p}^{2}=0.02$, evidenced that adults had lower digit ratios than children (Table 2).

Table 2. Descriptive statistics of digit ratios (in the left hand) of left- and right-handers among children and adults.

\begin{tabular}{|l|l|l|l|l|l|l|l|l|}
\hline & & Right-handers & & Left-handers & & & & \\
\hline Left hand & & $\boldsymbol{n}=\mathbf{1 5 7}$ & & $\boldsymbol{n}=\mathbf{1 3 3}$ & & & Total & \\
\hline Digit ratio & Age group & $\boldsymbol{M}$ & $\boldsymbol{S} \boldsymbol{D}$ & $\boldsymbol{M}$ & $\boldsymbol{S} \boldsymbol{D}$ & $\boldsymbol{d}$ & $\boldsymbol{M}$ & $\boldsymbol{S} \boldsymbol{D}$ \\
\hline 2D:3D & Children & 0.891 & 0.032 & 0.904 & 0.027 & $-0.44 *$ & 0.897 & 0.030 \\
\hline & Adults & 0.902 & 0.029 & 0.902 & 0.029 & 0.00 & 0.902 & 0.029 \\
\hline & Total & 0.898 & 0.030 & 0.902 & 0.028 & & & \\
\hline 2D:4D & Children & 0.965 & 0.046 & 0.964 & 0.029 & 0.03 & 0.965 & 0.040 \\
\hline & Adults & 0.970 & 0.032 & 0.970 & 0.038 & 0.00 & 0.970 & 0.035 \\
\hline & Total & 0.968 & 0.038 & 0.968 & 0.035 & & & \\
\hline 2D:5D & Children & 1.210 & 0.066 & 1.215 & 0.052 & -0.08 & 1.212 & 0.060 \\
\hline & Adults & 1.203 & 0.060 & 1.198 & 0.061 & 0.08 & 1.201 & 0.060 \\
\hline & Total & 1.206 & 0.062 & 1.204 & 0.058 & & & \\
\hline 3D:4D & Children & 1.083 & 0.031 & 1.067 & 0.036 & $0.48 *$ & 1.076 & 0.034 \\
\hline & Adults & 1.076 & 0.024 & 1.075 & 0.026 & 0.04 & 1.076 & 0.025 \\
\hline & Total & 1.079 & 0.027 & 1.073 & 0.030 & & & \\
\hline 3D:5D & Children & 1.359 & 0.076 & 1.345 & 0.057 & 0.21 & 1.353 & 0.068 \\
\hline & Adults & 1.335 & 0.066 & 1.329 & 0.064 & 0.09 & 1.332 & 0.065 \\
\hline & Total & 1.344 & 0.070 & 1.334 & 0.062 & & & \\
\hline 4D:5D & Children & 1.255 & 0.062 & 1.261 & 0.051 & -0.10 & 1.257 & 0.057 \\
\hline & Adults & 1.240 & 0.050 & 1.236 & 0.059 & 0.07 & 1.238 & 0.054 \\
\hline & Total & 1.246 & 0.055 & 1.244 & 0.057 & & & \\
\hline
\end{tabular}

Note. Number of children $=101 ;$ Number of adults $=189$.

$* p<.05$.

Regarding the direction of differences in digit ratios between left-handers vs. right-handers among children, the following pattern is discernible: as compared to right-handers, left-handers had lower digit ratios in the ratios containing digit 3 as numerator or digit 4 as denominator, whereas higher digit ratios in those containing digit 4 as numerator or digit 3 as denominator (Table 2). 


\subsection{Right hand}

\subsubsection{Digit length}

A MANOVA of digit length (four digit lengths), with hand preference, sex, and age group as factors, showed significant main effects of sex, $F(4,279)=8.16, p<.001, \eta_{p}{ }^{2}=0.11$, and age group, $F(4,279)=515.7, p<.001$, $\eta_{p}{ }^{2}=0.88$, and significant interaction effects of sex by age group, $F(4,279)=13, p<.001, \eta_{p}{ }^{2}=0.16$, and hand preference by age group, $F(4,279)=5.07, p=.001, \eta_{p}^{2}=0.07$.

Thus, compared to right-handers, left-handers had longer digits among children, but slightly shorter digits among adults (hand preference by age group interaction; Table 3). Although this effect was not significant for the length of digit 5, the direction of difference was similar to the one observed in other digit lengths (Table 3). As expected, men had longer digits than women, whereas there was no sex difference among children (sex by

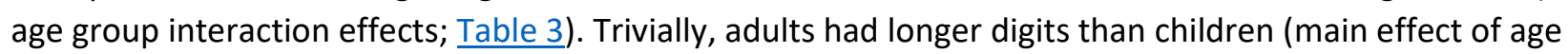
group; Table 3). 
Table 3. Descriptive statistics of digit lengths in right hand among children and adults.

\begin{tabular}{|c|c|c|c|c|c|c|c|c|c|c|c|c|c|c|}
\hline & & \begin{tabular}{|l|} 
Hand \\
preference
\end{tabular} & & & & & & Sex & & & & & & \\
\hline Right & & Right-handers & & $\begin{array}{l}\text { Left- } \\
\text { handers }\end{array}$ & & & $H \times A$ & Male & & Female & & $S \times A$ & & \\
\hline \multirow[t]{2}{*}{$\begin{array}{l}\text { Digit } \\
\text { length }\end{array}$} & $\begin{array}{l}\text { Age } \\
\text { group }\end{array}$ & $n=157$ & & $n=133$ & & & $F$ & $n=142$ & & $n=148$ & & $F$ & Total & \\
\hline & & $M$ & $S D$ & $M$ & $S D$ & $d$ & $\begin{array}{l}(1, \\
282)\end{array}$ & $M$ & $S D$ & $M$ & $S D$ & $\begin{array}{l}1, \\
282)\end{array}$ & $M$ & $S D$ \\
\hline \multirow[t]{2}{*}{$2 \mathrm{D}$} & Ch. & 4.62 & 0.37 & 4.82 & 0.39 & $-0.53^{*}$ & & 4.68 & 0.34 & 4.73 & 0.43 & & 4.71 & 0.39 \\
\hline & Ad. & 6.95 & 0.48 & 6.87 & 0.49 & 0.17 & $8.3^{\text {** }}$ & 7.17 & 0.43 & 6.65 & 0.41 & $35^{* * *}$ & 6.91 & 0.49 \\
\hline A, $F(1,282)$ & & & & & & & & & & & & & 1895*** & \\
\hline \multirow[t]{2}{*}{$3 \mathrm{D}$} & Ch. & 5.21 & 0.43 & 5.38 & 0.47 & $-0.38^{*}$ & & 5.24 & 0.39 & 5.33 & 0.50 & & 5.28 & 0.45 \\
\hline & Ad. & 7.72 & 0.56 & 7.67 & 0.58 & 0.09 & $5^{*}$ & 8.04 & 0.44 & 7.35 & 0.47 & $50 * *$ & 7.70 & 0.57 \\
\hline A, $F(1,282)$ & & & & & & & & & & & & & 1816*** & \\
\hline \multirow[t]{2}{*}{$4 \mathrm{D}$} & Ch. & 4.79 & 0.34 & 5.06 & 0.40 & $-0.74 * *$ & & 4.89 & 0.37 & 4.93 & 0.41 & & 4.91 & 0.39 \\
\hline & Ad. & 7.20 & 0.51 & 7.13 & 0.57 & 0.13 & $12^{* * *}$ & 7.48 & 0.46 & 6.85 & 0.41 & 47 *** & 7.16 & 0.54 \\
\hline A, $F(1,282)$ & & & & & & & & & & & & & 1902弚 & \\
\hline \multirow[t]{2}{*}{$5 \mathrm{D}$} & Ch. & 3.86 & 0.42 & 4.01 & 0.38 & -0.37 & & 3.92 & 0.35 & 3.93 & 0.45 & & 3.92 & 0.41 \\
\hline & Ad. & 5.78 & 0.49 & 5.78 & 0.52 & 0.00 & 2.2 & 6.05 & 0.40 & 5.51 & 0.45 & 30 *** & 5.78 & 0.50 \\
\hline $\mathrm{A}, F(1,282)$ & & & & & & & & & & & & & 1248 ** & \\
\hline
\end{tabular}

Note. 2D to 5D denote digit lengths; Ch. denotes children; Ad. denotes adults; $A$ denotes main effect of age group; $\mathrm{H} \times \mathrm{A}$ denotes hand preference by age group interaction effect; $\mathrm{S} \times \mathrm{A}$ denotes sex by age group interaction effect; Positive value of $d$ shows that right-handers have longer digit length; Number of children =101; Number of adults = 189; Number of right-handed adults = 100; Number of Men = 94 .

$* * p<.01$.

$* p<.05$. 


\subsubsection{Digit ratios}

A MANOVA of digit ratio (six digit ratios), with hand preference, sex, and age group as factors, showed a significant main effect of hand preference, $F(6,277)=2.18, p=.045, \eta_{p}{ }^{2}=0.05$, and a significant interaction effect of hand preference by age group, $F(6,277)=2.5, p=.02, \eta_{p}^{2}=0.05$.

Subsequent univariate ANOVAs showed interaction effects between hand preference and age group for the 3D:4D ratio, $F(1,282)=8.1, p=.005, \eta_{p}^{2}=0.03$. Thus, compared to right-handers, left-handers had lower 3D:4D ratio among children, but slightly higher 3D:4D ratio among adults (see Table 4). However, irrespective of the significant multivariate effects, univariate effects of hand preference were not significant for any of the digit ratios.

Table 4. Descriptive statistics of digit ratios (in right hand) of left- and right-handers among children and adults.

\begin{tabular}{|l|l|l|l|l|l|l|}
\hline & & Right-handers & & Left-handers & & \\
\hline Right hand & & $\boldsymbol{n}=\mathbf{1 5 7}$ & & $\boldsymbol{n}=\mathbf{1 3 3}$ & & \\
\hline Digit ratio & Age group & $\boldsymbol{M}$ & $\mathbf{S D}$ & $\boldsymbol{M}$ & $\mathbf{S D}$ & $\boldsymbol{d}$ \\
\hline 2D:3D & Children & 0.889 & 0.040 & 0.895 & 0.025 & -0.18 \\
\hline & Adults & 0.901 & 0.036 & 0.896 & 0.026 & 0.16 \\
\hline & Total & 0.897 & 0.038 & 0.896 & 0.026 & \\
\hline 2D:4D & Children & 0.965 & 0.042 & 0.953 & 0.030 & 0.33 \\
\hline & Adults & 0.966 & 0.036 & 0.965 & 0.036 & 0.03 \\
\hline & Total & 0.965 & 0.038 & 0.961 & 0.034 & \\
\hline 2D:5D & Children & 1.205 & 0.107 & 1.205 & 0.046 & 0.00 \\
\hline & Adults & 1.205 & 0.062 & 1.192 & 0.066 & 0.20 \\
\hline & Total & 1.205 & 0.081 & 1.196 & 0.061 & \\
\hline 3D:4D & Children & 1.086 & 0.051 & 1.065 & 0.033 & 0.49 \\
\hline & Adults & 1.072 & 0.034 & 1.077 & 0.025 & -0.17 \\
\hline & Total & 1.077 & 0.041 & 1.073 & 0.028 & \\
\hline 3D:5D & Children & 1.357 & 0.129 & 1.346 & 0.057 & 0.11 \\
\hline & Adults & 1.338 & 0.070 & 1.330 & 0.068 & 0.12 \\
\hline & Total & 1.345 & 0.096 & 1.336 & 0.065 & \\
\hline 4D:5D & Children & 1.249 & 0.092 & 1.265 & 0.050 & -0.22 \\
\hline & Adults & 1.248 & 0.052 & 1.235 & 0.061 & 0.23 \\
\hline
\end{tabular}

Note. Number of children $=101$; Number of adults $=189$.

$* p<.05$.

Moreover, it is observable from $\underline{\text { Table } 4}$ that, among children, left-handers had lower mean values of digit ratios containing digit 3 as numerator or digit 4 as denominator, and higher mean values of digit ratios containing digit 4 as numerator or digit 3 as denominator (as compared to right-handers).

\subsection{Composite digit lengths and digit ratios}

Fig. 1 shows the differences in composite (i.e., average of all) digit lengths, and Fig. 2 the respective differences in composite (i.e., average of left-hand and right-hand) digit ratios, between right-handers vs. left-handers among children vs. adults. In order to control for possible cultural confounds (religious affiliation), the effects of hand preference, sex, and age group on digit lengths and ratios were only analyzed in the Hindu sample, which yielded similar patterns of hand preference by age group interaction effects for both digit lengths and digit ratios (see Analysis of Digit Length and Digit Ratios in Hindu-Only Sample in the supplemental materials). 


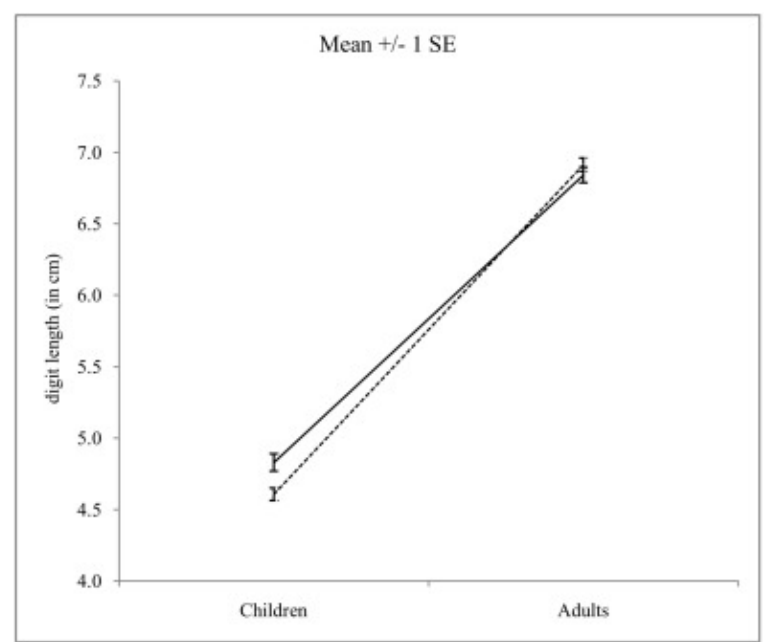

Fig. 1. The graph shows the mean and standard error of digit length in right- (---) and left- (__ $)$ handers among children and adults. Compared to right-handers, left-handers have longer digits among children, but shorter digits among adults.

(A)

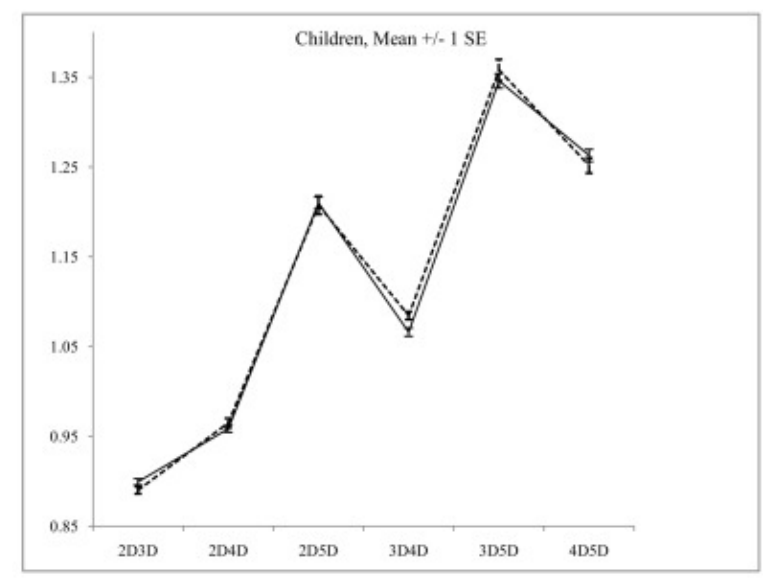

(B)

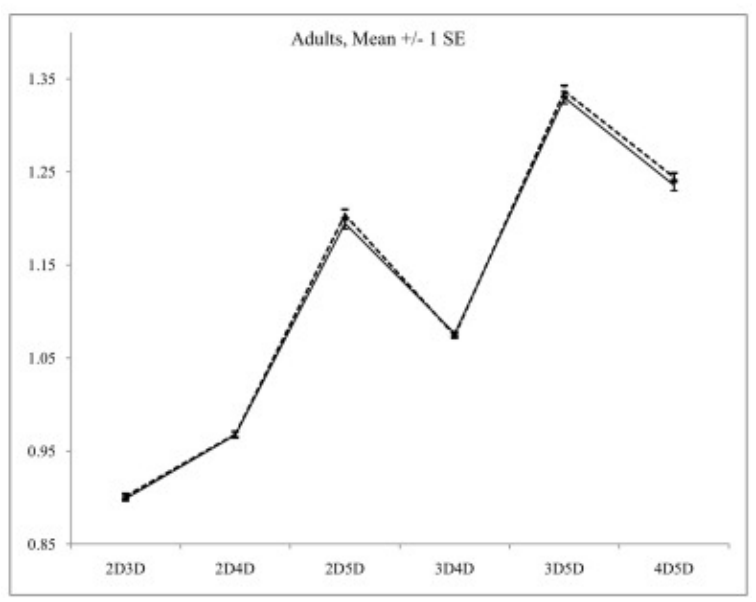

Fig. 2. The graphs show the mean and standard error of digit ratios of right- (---) and left- (__) handers among children (A) and adults (B). A pattern of opposite handed difference occurs in digit ratios involving digits 3 and 4 (at the same position, numerator or denominator) among children, and this pattern is reversed among adults.

\subsection{Right-minus-left digit ratio}

We analyzed the effects of hand preference, sex, and age group on right-minus-left digit ratio (Dr-I) across all six digit ratios. The interaction effect of hand preference by age group nominally was not significant, $F(6$, 
$277)=2.06, p=.06$, and all other effects were even smaller and clearly not significant, Fs(6,

$277)<1.18$, ps $>0.32$. For future references, we have reported the results for right-minus-left differences in digit ratios for hand preference and sex across age groups (see Distribution of Right-Minus-Left Digit Ratios in the supplemental materials).

\section{Discussion}

Sex differences in digit length (i.e., strong differences among adults, but a lack of the same differences among children) are a commonly observed phenomenon [9]. As well, lower digit ratios (comprising digit 5) among adults than in children, as observed in this study, are consistent with prior reports [42].

Our main contention was that similar effects of hand preference on digit lengths and digit ratios suggest the involvement of a common genetic mechanism. The present study reports such a similar effect of hand preference on digit lengths and ratios alike (among children, as well as - directionally reversed - among adults) and thus is consistent with the above idea. Moreover, because a cascade mechanism determines the development of the hand [50], it is conceivable that upstream effects of hand preference could regulate the developmental genetic mechanism of hand formation, thus accounting for similar effects seen in both digit lengths and digit ratios.

Prior related research has reported that either there are no handedness differences in 2D:4D [[11], [12], [13], [14], [15]], or that adult right-handers have higher 2D:4D [[8], [9], [10]]. Similarly, we found that either there are no handedness differences in digit ratios, or that adult right-handers have a trend of a higher 3D:4D. Therefore, these findings seem typical for adults. On the other hand, this study is one of the up to now very few more comprehensive reports on hand-preference effects on digit ratios among children in particular. The relationship of right-hand preference with higher 3D:4D, as reported here, is similar to prior reports on a relationship of enhanced right-hand skills (a measure of right-handedness) with higher 2D:4D among children $[\underline{43}, \underline{44}]$. In this regard, the present data appear typical for children as well.

Additional results of the present study (namely, that effects of hand preference are strongest for the 3D:4D ratio, and that there is an opposite pattern of effects on digit ratios containing the digits 3 and 4 at the same position) suggest that the lengths of digits 3 and 4 also stand out as factors with regards to hand-preference effects on digit ratios. However, the main factors regarding the magnitude of sex differences in digit ratios are the lengths of digits 2 and 5 [[45], [46], [47], [48],56]. The present data suggest that the developmental programs mediating effects of hand preference on digit ratios may be different from the structural programs mediating the effects of sex.

Sex effects on digit ratios are established early on [57] and either remain stable or increase with age (even after puberty, $[41, \underline{42}, \underline{57}])$, whereas the effects of hand preference (as observed in the present study) directionally are opposite among children vs. among adults. Because higher testosterone exposure has been shown to be related to lower digit ratios in both infants $[\underline{1}, \underline{2}]$ and adults $[\underline{57}, \underline{58}]$, the effects of hand preference on digit ratios, unlike the sex effects, conceivably are less likely determined by prenatal or pubertal sex-hormone levels. Moreover, because study participants were from the same catchment area and the finger-length measurement protocol was identical for the children and the adult sample, confounding effects of measurement procedure or ethnicgeographic differences do not affect the present study.

For these reasons, a simple explanation of the reversal of hand-preference effects on digit lengths and digit ratios among adults would be some ontogenetic mechanism. However, studies have reported that the interaction of postnatal testosterone levels with androgen sensitivity (as measured through the CAG repeat sequences found in the human androgen-receptor gene) impacts on early developmental changes in digit ratios [ㄷ]. There is evidence that left-handed adults might have higher testosterone levels [60] and lower androgen 
sensitivity (in women; [61]). Higher androgen sensitivity (i.e., shorter CAG repeat sequences) has been associated with more marked age-related declines in androgen levels (in men; [62]). Moreover, some studies suggest that digit ratios (2D:4D) increase with age until early adulthood (17 years of age; [41,63]) and decrease thereafter $[\underline{63}, 64]$. Thus, a three-way interaction effect comprised of sex-hormone sensitivity, age, and sexhormone levels is conceivable (accounting for the reversed hand-preference effects on digit ratios among adults). However, because an integrated and self-regulated gene program (with catch-up and cessation mechanisms) monitors the overall growth of organs, any normal-range variations between left-handers and right-handers in digit lengths and ratios (or in sex-hormone levels and hormonal sensitivities) may be expressions of the same basic ontogenetic program $[\underline{65}, \underline{66}]$.

In schizophrenia patients, reversals of the usual sexual dimorphisms in brain structure [67,68], as well as in digit ratios (2D:4D; [[69], [70], [71]]), have been observed. Evidence suggests that such reversals are genetically based $[\underline{72}, \underline{73}]$. Moreover, schizophrenia is related to non-right hand preference (a marker of atypical cerebral lateralization; [74]), and a common genetic and structural mechanism mediates this relationship [ㄷ] ]. Thus, a reversal of sex differences seen in digit ratios (as well as in brain structures), and associated with schizophrenia or hand preference, maybe genetically determined.

Studies have reported a genetically based relationship of height with brain volume and brain surface area [ㄷ] . Because digit length and height are closely related (with similar growth patterns mediated by puberty [9]]), relationships of digit lengths with brain volume and total brain surface area are conceivable. Digit ratios (2D:4D) have also been reported to be related to larger total cerebral cortex volume [77]. The formation of hands and the brain involves common genes [50,[78], [79], [80]]. Moreover, differing maturation rates, as occurring on the left vs. the right side of the spinal cord and the brain during weeks 4 to 8 of intrauterine development, are key mediators of hand preference and schizophrenia development $[\underline{181}, \underline{82}]$. Thus, although any one-to-one correspondence regarding the growth trajectories of brain and digit lengths are unlikely [83], it may well be that common genetic mechanisms mediate the differential growth trajectories of left-handers vs. right-handers in digit lengths, digit ratios, and the brain.

The present evidence has a number of implications for digit ratio research. One prior report found that differential growth trajectories occur for the digit ratios of some individuals (when compared to average agerelated trends), the reasons of which are unknown [84]. Therefore, based on the present findings, we suggest that hand preference might be a determining factor for such differential growth trajectories in digit ratios. Moreover, we also opine that including participants from different growth periods in one and the same sample may be a confounding factor in studies on the relationship between hand preference and digit ratios and should thus be avoided, or appropriately accounted for in the analytic strategy.

Prior studies have reported negative [[85], [86], [87]], positive [88, $\underline{89}]$, or no [이, $\underline{91}]$ relationships between age of puberty onset and digit ratios (2D:4D). Because left-handers and right-handers apparently have differential growth trajectories of digit ratios (as suggested by the present findings), it is likely that, in turn, hand preference is a confounding factor in investigations on the relationship between age of pubertal onset and digit ratios.

Moreover, specific findings in the course of the present investigation (namely, that hand-preference effects are stronger for 3D:4D than for 2D:4D) suggest that previous studies on hand-preference effects may well have focused on a noisy indicator (the commonly studied 2D:4D ratio, instead on 3D:4D). However, because studies have reported that the occurrence of the largest sex differences in digit ratios may vary with geography and/or ethnic group $[\underline{45}, \underline{48}, \underline{92}]$, this hypothesis is tentative, until future studies in other ethnic-geographic populations support it. 
The present study has a number of limitations. First, left-handers and right-handers were not matched for the degree, or strength, of their hand preference. However, because prior studies [12], as well as a supplemental analysis of the present data (not shown), have not yielded evidence for relationships between degree of hand preference and digit lengths or ratios, degree of hand preference may not have confounded effects. Second, because left-handers represent a heterogeneous group (determined by a suite of genetic and environmental factors; [93]), the nature of hand preference (based on its determinants) in any sample of left-handers may be yet another confounder (and thus common to all investigations of hand preference). However, because it is difficult to ascertain the exact determinants of left-hand preference in any individual [93], we can only expect that in a sufficiently large sample of left-handers from the healthy population (as in the present study) unusual or pathological confounding effects would cancel each other out. And third, we measured digit length directly on the palmar side of the hand, whereas the placing of flexion creases and dorsal (i.e., bone-based) digit length are distinct components of this measure, and these components may be the results of distinctive determinants [94]. On the other side, because prior studies on hand-preference effects were mainly based on digit ratios derived from measures of the palmar side of the hand, the present study has the advantage of enabling direct comparisons with the findings of these predecessor studies.

Hence, in conclusion, the present study suggests that gene-based mechanisms mediate the effects of hand preference on digit lengths and digit ratios, and that differential growth trajectories may occur for digit lengths and digit ratios of left-handers vs. right-handers. The findings also call for longitudinal investigations concerned with hand-preference effects on digit lengths and digit ratios as a fruitful avenue along this line of inquiry.

\section{CRediT authorship contribution statement}

Sanjay Kumar: Conceptualization, Methodology, Formal analysis, Writing- Original draft preparation. Maharaj Singh: Conceptualization, Methodology, Formal analysis, Reviewing and Editing, Supervision. Martin Voracek: Formal analysis, Writing- Reviewing and Editing, Supervision.

\section{References}

[1] S. Lutchmaya, S. Baron-Cohen, P. Raggatt, R. Knickmeyer, J.T. Manning. 2nd to 4th digit ratios, fetal testosterone and estradiol. Early Hum. Dev., 77 (2004), pp. 23-28

[2] T. Ventura, M.C. Gomes, A. Pita, M.T. Neto, A. Taylor. Digit ratio (2D:4D) in newborns: influences of prenatal testosterone and maternal environment. Early Hum. Dev., 89 (2013), pp. 107-112

[3] N. Geschwind, A.M. Galaburda. Cerebral lateralization biological mechanisms, association and pathology: a hypothesis and a program for research. Arch. Neurol., 43 (1985), pp. 428-654

[4] S.F. Witelson. Neural sexual mosaicism: sexual differentiation of the human temporo-parietal region for functional asymmetry. Psychoneuroendocrinology, 16 (1991), pp. 131-153, 10.1016/03064530(91)90075-5

[5] M.E. Nicholls, C.A. Orr, M.J. Yates, A.M. Loftus. A new means of measuring index/ring finger (2D:4D) ratio and its association with gender and hand preference. Laterality, 13 (2008), pp. 71-91

[6] M. Voracek, B. Reimer, C. Ertl, S.G. Dressler. Digit ratio (2D:4D), lateral preferences, and performance in fencing. Percept. Mot. Skills, 103 (2006), pp. 427-446

[7] J.T. Manning, M. Peters. Digit ratio (2D:4D) and hand preference for writing in the BBC Internet Study. Laterality, 14 (2009), pp. 528-540

[8] L. Kalichman, V. Batsevich, E. Kobyliansky. Digit ratio and laterality indices: the Chuvashian study. Pap. Anthropol., 23 (2014), pp. 37-46, 10.12697/poa.2014.23.2.03

[9] L. Gillam, R. McDonald, F.J.P. Ebling, T.M. Mayhew. Human 2D (index) and 4D (ring) finger lengths and ratios: cross-sectional data on linear growth patterns, sexual dimorphism and lateral asymmetry from 4 to 60 years of age. J. Anat., 213 (2008), pp. 325-335, 10.1111/j.1469-7580.2008.00940.x 
[10] A. Ypsilanti, M. Ganou, I. Koidou, G. Grouios. Digit ratio (2D:4D) in individuals with intellectual disability: investigating the role of testosterone in the establishment of cerebral lateralization. Laterality, 13 (2008), pp. 527-544, 10.1080/13576500802117164

[11] A.A. Beaton, N. Rudling, C. Kissling, R. Taurines, J. Thome. Digit ratio (2D:4D), salivary testosterone, and handedness. Laterality, 16 (2011), pp. 136-155

[12] C.J. Choudhary. Why Laterality Matters in Trauma: Sinister Aspects of Memory and Emotion, a Thesis Submitted in Partial Fulfillment for the Degree of Doctor of Philosophy in the Dept. of Psychology, Univ. of Sterling, UK. Available from https://dspace.stir.ac.uk/.../1/thesis-final-version-minusapp24.pdf (2008)

[13] J. Robertson, W. Zhang, J.J. Liu, K.R. Muir, R.A. Maciewicz, M. Doherty. Radiographic assessment of the index to ring finger ratio (2D:4D) in adults. J. Anat., 212 (2008), pp. 42-48

[14] Z. Stoyanov, M. Marinov, I. Pashalieva. Finger length ratio (2D:4D) in left- and right-handed males. Int. J. Neurosci., 119 (2009), pp. 1006-1013

[15] Z. Stoyanov, I. Pashalieva, P. Nikolova. Finger length ratio (2D:4D) in left- and right-handed females: evidence supporting Geschwind and Galaburda hypothesis. Journal of Asymmetry, 5 (2011), pp. 20-26

[16] J.M. Hudson, J.C. Hodgson. Is digit ratio (2D:4D) a reliable pointer to speech laterality? Behav. Brain Res., 301 (2016), pp. 258-261, 10.1016/j.bbr.2015.12.042

[17] M. Papadatou-Pastou, M. Martin. Cerebral laterality for language is related to adult salivary testosterone levels but not digit ratio (2D: 4D) in men: a functional transcranial Doppler ultrasound study. Brain Lang., 166 (2017), pp. 52-62

[18] D.A. Puts, M.A. McDaniel, C.L. Jordan, S.M. Breedlove. Spatial ability and prenatal androgens: metaanalyses of congenital adrenal hyperplasia and digit ratio (2D:4D) studies. Arch. Sex. Behav., 37 (2008), pp. 100-111, 10.1007/s10508-007-9271-3

[19] J.T. Manning, S. Wood, E. Vang, J. Walton, P.E. Bundred, C. van Heyningen, D.I. Lewis-Jones. Second to fourth digit ratio (2D:4D) and testosterone in men, Asian. J. Androl., 6 (2004), pp. 211-215

[20] L.P. Hollier, J.A. Keelan, E.S. Jamnadass, M.T. Maybery, M. Hickey, A.J. Whitehouse. Adult digit ratio (2D:4D) is not related to umbilical cord androgen or estrogen concentrations, their ratios or net bioactivity. Early Hum. Dev., 91 (2015), pp. 111-117, 10.1016/j.earlhumdev.2014.12.011

[21] G. Richards, M. Gomes, T. Ventura. Testosterone measured from amniotic fluid and maternal plasma shows no significant association with directional asymmetry in newborn digit ratio (2D:4D). J. Dev. Orig. Health Dis., 10 (2019), pp. 362-367, 10.1017/S2040174418000752

[22] R.A. Lippa. Are 2D: 4D finger-length ratios related to sexual orientation? Yes for men, no for women. J. Pers. Soc. Psychol., 85 (2003), pp. 179-188

[23] J.T. Manning, B. Fink. Digit ratio (2D:4D), dominance, reproductive success, asymmetry, and sociosexuality in the BBC Internet Study. Am. J. Hum. Biol., 20 (2008), pp. 451-461, 10.1002/ajhb.20767

[24] M. Voracek, S.G. Dressler. Digit ratio (2D:4D) in twins: heritability estimates and evidence for a masculinized trait expression in women from opposite-sex pairs. Psychol. Rep., 100 (2007), pp. 115$126,10.2466 /$ pro.100.1.115-126

[25] M. Voracek, S.G. Dressler. Brief communication: familial resemblance in digit ratio (2D:4D). Am. J. Phys. Anthropol., 140 (2009), pp. 376-380, 10.1002/ajpa.21105

[26] K.L. Gobrogge, S.M. Breedlove, K.L. Klump. Genetic and environmental influences on 2D:4D finger length ratios: a study of monozygotic and dizygotic male and female twins. Arch. Sex. Behav., 37 (2008), pp. $112-118$

[27] S.N. Paul, B.S. Kato, L.F. Cherkas, T. Andrew, T.D. Spector. Heritability of the second to fourth digit ratio (2D:4D): a twin study. Twin Res. Hum. Genet., 9 (2006), pp. 215-219

[28] S.E. Medland, T. Zayats, B. Glaser, D.R. Nyholt, S.D. Gordon, M.J. Wright, et al. A variant in LIN28B is associated with 2D:4D finger-length ratio, a putative retrospective biomarker of prenatal testosterone exposure0 Am. J. Hum. Genet., 86 (2010), pp. 519-525

[29] E. Widen, S. Ripatti, D.L. Cousminer, I. Surakka, T. Lappalainenet. al., Distinct variants at LIN28B influence growth in height from birth to adulthood. Am. J. Hum. Genet., 86 (2010), pp. 773-782 
[30] P. Nikolova, Z. Stoyanov, N. Negrev. Functional brain asymmetry, handedness and menarcheal age. Int. J. Psychophysiol., 18 (1994), pp. 213-215

[31] Z. Orbak. Does handedness and altitude affect age at menarche? J. Trop. Pediatr., 51 (2005), pp. 216-218

[32] C. Barut, U. Tan, A. Dogan. Association of height and weight with second to fourth digit ratio (2D:4D) and sex differences. Percept. Mot. Skills, 106 (2008), pp. 627-632

[33] E.L. Abel, M.L. Kruger. Lefties are still a little shorter. Percept. Mot. Skills, 104 (2007), pp. 405-406

[34] R. Pollard. A difference in heights and weights between right-handed and left-handed bowlers at cricket. Percept. Mot. Skills, 81 (1995), pp. 601-602

[35] K. Silventoinen, J. Haukka, L. Dunkel, P. Tynelius, F. Rasmussen. Genetics of pubertal timing and its associations with relative weight in childhood and adult height: the Swedish young male twins study. Pediatrics, 121 (2008), pp. e885-e891, 10.1542/peds.2007-1615

[36] J.P. Bonjour, T. Chevalley. Pubertal timing, peak bone mass and fragility fracture risk. BoneKEy Osteovision, 4 (2007), pp. 30-48, 10.1138/20060247

[37] A.P. McMechan, S.K. O'Leary-Moore, S.D. Morrison, J.H. Hannigan. Effects of prenatal alcohol exposure on forepaw digit length and digit ratios in rats. Dev. Psychobiol., 45 (2004), pp. 251 258, 10.1002/dev.20035

[38] M. Voracek, J. Pietschnig. Digit ratios, finger length, and basic musical abilities. Psychol. Belg., 49 (2009), pp. 1-18, 10.5334/pb-49-1-1

[39] A.G. Sutcliffe, J.T. Manning, A. Katalanic, A. Ludwig, M. Mehta, et al. Perturbations in finger length and digit ratio (2D:4D) in ICSI children. Reprod. BioMed. Online, 20 (2010), pp. 138$143,10.1016 / j . r b m o .2009 .10 .023$

[40] J.T. Manning. Digit Ratio: A Pointer to Fertility, Behavior, and Health. Rutgers University, New Brunswick, NJ (2002)

[41] H.M. McIntyre, P.T. Ellison, D.E. Lieberman, E. Demerath, B. Towne. The development of sex differences in digital formula from infancy in the fels longitudinal study. Proc. R. Soc. Lond. [Biol], 272 (2005), pp. 1473-1479

[42] R. Trivers, J.T. Manning, A. Jacobson. A longitudinal study of digit ratio (2D:4D) and other finger ratios in Jamaican children. Horm. Behav., 49 (2006), pp. 150-156

[43] B. Fink, J.T. Manning, N. Neave, U. Tan. Second to fourth digit ratio and hand skill in Austrian children. Biol. Psychol., 67 (2004), pp. 375-385

[44] J.T. Manning, R.L. Trivers, R. Thornhill, D. Singh. The 2nd: 4th digit ratio and asymmetry of hand performance in Jamaican children. Laterality, 5 (2000), pp. 121-132

[45] J.C. Loehlin, S.E. Medland, N.G. Martin. Relative finger lengths, sex differences, and psychological traits. Arch. Sex. Behav., 38 (2009), pp. 298-305, 10.1007/s10508-007-9303-z

[46] D. McFadden, M.S. Bracht. Sex and race differences in the relative lengths of metacarpals and metatarsals in human skeletons. Early Hum. Dev., 85 (2009), pp. 117-124

[47] H.M. Mclntyre, B.A. Cohn, P.T. Ellison. Sex dimorphism in digital formulae of children. Am. J. Phys. Anthropol., 129 (2006), pp. 143-150

[48] M. Voracek. Comparative study of digit ratios (2D:4D and other) and novel measures of relative finger length: testing magnitude and consistency of sex differences across samples. Percept. Mot. Skills, 108 (2009), pp. 83-93

[49] R. Kosif, M. Diramali. Comparison of all hand digit length ratios in left - and right- handed individuals. Turk. J. Med. Sci., 42 (2012), pp. 1-8, 10.3906/sag-1006-858

[50] N. Shubin, C. Tabin, S. Carroll. Fossils, genes and the evolution of animal limb. Nature, 388 (1997), pp. 639648

[51] J.T. Manning, A.J. Churchill, M. Peters. The effects of sex, ethnicity, and sexual orientation on selfmeasured digit ratio (2D:4D). Arch. Sex. Behav., 36 (2007), pp. 223-233, 10.1007/s10508-007-9171-6

[52] J.T. Manning, A. Stewart, P.E. Bundred, R.L. Triver. Sex and ethnic differences in $\mathbf{2 n d}$ to $\mathbf{4}^{\text {th }}$ digit ratio of children. Early Hum. Dev., 80 (2004), pp. 161-168, 10.1016/j.earlhumdev.2004.06.004 
[53] M. Singh, M. Manjary, G. Dellatolas. Lateral preference among Indian school children. Cortex, 37 (2001), pp. 231-241

[54] R.C. Oldfield. The assessment and analysis of handedness: the Edinburgh inventory. Neuropsychologia, 9 (1971), pp. 97-113

[55] S. Kumar, R. Saini, R. Jain. Hand preference and intolerance of uncertainty: atypical cerebral lateralization advantages lower intolerance of uncertainty. Laterality, 25 (2020), pp. 2242, 10.1080/1357650X.2019.1611843

[56] S. Kumar, M. Voracek, M. Singh. Sexual dimorphism in digit ratios derived from dorsal digit length among adults and children, Front. Endocrinol. (Lausanne), 8 (2017), p. 41, 10.3389/fendo.2017.00041

[57] J.T. Manning, D. Scutt, J. Wilson, D.I. Lewis-Jones. The ratio of 2 nd and 4th digit length: a predictor of sperm number and concentrations of testosterone, luteinizing hormone and oestrogen. Hum. Reprod., 13 (1998), pp. 3000-3004

[58] M. Klimek, A. Galbarczyk, I. Nenko, L.C. Alvarado, G. Jasienska. Digit ratio (2D:4D) as an indicator of body size, testosterone concentration and number of children in human males. Ann. Hum. Biol., 41 (2014), pp. 518-523, 10.3109/03014460.2014.902993

[59] R.C. Knickmeyer, S. Woolson, R.M. Hamer, T. Konneker, J.H. Gilmore. 2D:4D ratios in the first 2 years of life: stability and relation to testosterone exposure and sensitivity. Horm. Behav., 60 (2011), pp. 256263, 10.1016/j.yhbeh.2011.05.009

[60] C. Faurie, V. Llaurens, A. Alvergne, M. Goldberg, M. Zins, M. Raymond. Left-handedness and male-male competition: insights from fighting and hormonal data. Evol. Psychol., 9 (2011) (147470491100900307)

[61] L. Arning, S. Ocklenburg, S. Schulz, V. Ness, W.M. Gerding, J.G. Hengstler, et al. Handedness and the X chromosome: the role of androgen receptor CAG-repeat length. Sci. Rep., 5 (2015), p. $8325,10.1038 /$ srep08325

[62] K. Krithivas, S.M. Yurgalevitch, B.A. Mohr, C.J. Wilcox, S.J. Batter, et al. Evidence that the CAG repeat in the androgen receptor gene is associated with the age-related decline in serum androgen levels in men. $J$. Endocrinol., 162 (1999), pp. 137-142

[63] G. Richards, W. Bellin, W. Davies. Familial digit ratio (2D:4D) associations in a general population sample from Wales. Early Hum. Dev., 112 (2017), pp. 14-19, 10.1016/j.earlhumdev.2017.06.006

[64] S. Van Dongen. Second to fourth digit ratio in relation to age, BMI and life history in a population of young adults: a set of unexpected results. J. Negat. Results, 6 (2009), pp. 1-7

[65] J.C. Lui, P. Garrison, J. Baron. Regulation of body growth. Curr. Opin. Pediatr., 27 (2015), pp. 502510, 10.1097/MOP.0000000000000235

[66] A. Roselló-Díez, A.L. Joyner. Regulation of long bone growth in vertebrates: it is time to catch up. Endocr. Rev., 36 (2015), pp. 646-680, 10.1210/er.2015-1048

[67] S.L. Collinson, C.E. Mackay, A.C. James, D.J. Quested, T. Phillips, et al. Brain volume, asymmetry and intellectual impairment in relation to sex in early-onset schizophrenia. Br. J. Psychiatry, 183 (2003), pp. $114-120$

[68] A. Mendrek. Reversal of normal cerebral sexual dimorphism in schizophrenia: evidence and speculations. Med. Hypotheses, 69 (2007), pp. 896-902

[69] M. Arato, E. Frecska, C. Beck, M. An, H. Kiss. Digit length pattern in schizophrenia suggests disturbed prenatal hemispheric lateralization. Prog. Neuro-Psychopharmacol. Biol. Psychiatry, 28 (2004), pp. 191194

[70] S.L. Collinson, M. Lim, J.H. Chaw, S. Verma, K. Sim, et al. Increased ratio of 2nd to 4th digit (2D:4D) in schizophrenia. Psychiatry Res., 176 (2010), pp. 8-12, 10.1016/j.psychres.2009.08.023

[71] G. Venkatasubramanian, R. Arasappa, N.P. Rao, B.N. Gangadhar. Digit ratio (2D:4D) asymmetry and schneiderian first rank symptoms: implications for cerebral lateralization theories of schizophrenia. Laterality, 16 (2011), pp. 499-512

[72] T.J. Crow. Schizophrenia as failure of hemispheric dominance for language. Trends Neurosci., 20 (1997), pp. 339-343 
[73] A. Divakaran, J.C. Narayanaswamy, S.V. Kalmady, V. Narayan, N.P. Rao, G. Venkatasubramanian. Family history correlates of digit ratio abnormalities in schizophrenia. Indian J. Psychol. Med., 34 (2012), pp. 355-359, 10.4103/0253-7176.108220

[74] I. Sommer, N. Ramsey, R. Kahn, A. Aleman, A. Bouma. Handedness, language lateralisation and anatomical asymmetry in schizophrenia: meta-analysis. Br. J. Psychiatry, 178 (2001), pp. 344-351

[75] A. Wiberg, M. Ng, Y. Al Omran, F. Alfaro-Almagro, P. McCarthy, et al. Handedness, language areas and neuropsychiatric diseases: insights from brain imaging and genetics. Brain, 142 (2019), pp. 29382947, 10.1093/brain/awz257

[76] E. Vuoksimaa, M.S. Panizzon, C.E. Franz, C. Fennema-Notestine, D.J. Hagler, et al. Brain structure mediates the association between height and cognitive ability. Brain Struct. Funct., 223 (2018), pp. 34873494, 10.1007/s00429-018-1675-4

[77] G. Darnai, E. Plózer, G. Perlaki, G. Orsi, S.A. Nagy, et al. 2D:4D finger ratio positively correlates with total cerebral cortex in males. Neurosci. Lett., 615 (2016), pp. 33-36

[78] T. Fukuchi-Shimogori, E.A. Grove. Neocortex patterning by the secreted signaling molecule FGF8. Science, 294 (2001), pp. 1071-1074

[79] M.P. O'Rourke, P.P.L. Tam. Twist functions in mouse development. Int. J. Dev. Biol., 46 (2002), pp. 401-413

[80] B.A. Parr, M.J. Shea, G. Vassileva, A.P. McMohan. Mouse wnt genes exhibit discrete domains of expression in the early embryonic CNS and limb buds. Development, 119 (1993), pp. 247-261

[81] C.G.F. de Kovel, S.N. Lisgo, G. Karlebach, J. Ju, G. Cheng, et al. Left-right asymmetry of maturation rates in human embryonic neural development. Biol. Psychiatry, 82 (2017), pp. 204$212,10.1016 / \mathrm{j}$. biopsych.2017.01.016

[82] C.G.F. de Kovel, S.N. Lisgo, S.E. Fisher, C. Francks. Subtle left-right asymmetry of gene expression profiles in embryonic and foetal human brains. Sci. Rep., 8 (2018), Article 12606, 10.1038/s41598-018-29496-2

[83] R.K. Lenroot, N. Gogtay, D.K. Greenstein, E.M. Wells, G.L. Wallace, et al. Sexual dimorphism of brain developmental trajectories during childhood and adolescence. Neuroimage, 36 (2007), pp. 1065-1073

[84] M. Králík, P. Ingrová, S. Kozieł, A. Hupková, O. Klíma. Overall trends vs. individual trajectories in the second-to-fourth digit (2D:4D) and metacarpal (2M:4M) ratios during puberty and adolescence. Am. J. Phys. Anthropol., 162 (2017), pp. 641-656, 10.1002/ajpa.23153

[85] L. Kalichman, V. Batsevich, E. Kobyliansky. 2D:4D finger length ratio and reproductive indices in a Chuvashian population. Am. J. Hum. Biol., 25 (2013), pp. 617-621

[86] R.L. Matchock. Low digit ratio (2D:4D) is associated with delayed menarche. Am. J. Hum. Biol., 20 (2008), pp. 487-489

[87] J.T. Manning, B. Fink. Is low digit ratio linked with late menarche? Evidence from the BBC internet study. Am. J. Hum. Biol., 23 (2011), pp. 527-533

[88] D.C. Gooding, B.H. Chambers. Age of pubertal onset and 2nd to 4th digit ratios: preliminary findings. Early Hum. Dev., 116 (2018), pp. 28-32, 10.1016/j.earlhumdev.2017.10.007

[89] A.S. Oberg, E. Villamor. Low digit ratio predicts early age at menarche in Colombian school girls. Paediatr. Perinat. Epidemiol., 26 (2012), pp. 448-455, 10.1111/j.1365-3016.2012.01310.x

[90] S. Helle. Does second-to-fourth digit length ratio (2D:4d) predict age at menarche in women? Am. J. Hum. Biol., 22 (2010), pp. 418-420

[91] D.C. Muller, L. Baglietto, J.T. Manning, C. McLean, J.L. Hopper, et al. Second to fourth digit ratio (2D:4D), breast cancer risk factors, and breast cancer risk: a prospective cohort study. Br. J. Cancer, 107 (2012), pp. 1631-1636

[92] D. McFadden, E. Shubel Relative lengths of fingers and toes in human males and females. Horm. Behav., 42 (2002), pp. 492-500, 10.1006/hbeh. 2002.1833

[93] J. Schmitz, G.A.S. Metz, O. Güntürkün, S. Ocklenburg. Beyond the genome: towards an epigenetic understanding of handedness ontogenesis. Prog. Neurobiol., 159 (2017), pp. 6989, 10.1016/j.pneurobio.2017.10.005 
[94] S. Kumar, M. Voracek, M. Singh. Differential placing of flexion creases contributes to sex differences in the second-to-fourth digit ratio (2D: 4D). Front. Endocrinol. (Lausanne), 10 (2019),

p. $537,10.3389 /$ fendo. 2019.00537 